\title{
Innovation for environmental sustainability: longitudinal effects of an education for sustainable development intervention on university students' pro-environmentalism
}

Sustainable development intervention
Received 28 July 2021 Revised 21 October 2021 25 November 2021 Accepted 30 November 2021

\author{
Silvia Collado, José David Moreno and José Martín-Albo \\ Department of Psychology and Sociology, University of Zaragoza, Teruel, Spain
}

\begin{abstract}
Purpose - Although education for sustainable development (ESD) is a key tool in the transition to a more sustainable society, its integration in higher education remains scarce. One reason for this is that more evidence is needed about the effectiveness of ESD interventions. This study aims to address this gap in the literature by examining the immediate and long-term effects of an ESD intervention on university students' pro-environmental knowledge, personal environmental norm and proenvironmental behaviors.

Design/methodology/approach - This study used a quasi-experimental design that examined to what extent participating in an ESD intervention influenced university students' self-reported proenvironmentalism (i.e. experimental group), compared to those who did not participate in the ESD intervention (i.e. control group). The authors also examined the longitudinal effects of the ESD intervention by recording students' pro-environmentalism (both in the experimental and control group) 1 year after the intervention.

Findings - The findings showed that participation in the ESD intervention enhanced students' proenvironmental knowledge, personal environmental norms and pro-environmental behaviors relative to the noparticipation control group. The positive effects of the ESD intervention remained 1 year after the program finished.

Originality/value - This work explores the effects that ESD interventions have on university students. Its findings provide evidence about the effectiveness of the intervention and, therefore, support the inclusion of ESD at higher educational levels.
\end{abstract}

Keywords Environmental education, Higher education, Follow up, Environmental norms, Long term effects, Quasi-experimental design intervention

Paper type Research paper

This study falls within the framework of two educational innovation projects coordinated by the first author (PIIDUZ_18_157 and PIIDUZ_19_048). It is supported by the Spanish Ministry of Science, Innovation and Universities (grant number: PGC2018-095502-B-I00) and Decanato de la Facultad de Ciencias Sociales y Humanas (Universidad de Zaragoza). The latter helped us to identify sustainability researchers and professionals who designed and conducted the ESD intervention. The authors are grateful for the support provided by all institutions, especially of Oficina Verde de la Universidad de Zaragoza.

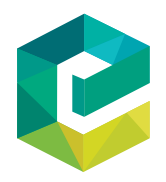

International Journal of Sustainability in Higher Education (c) Emerald Publishing Limited $1467-6370$
DOI 10.1108/IJSHE-07-2021-0315 


\section{Introduction}

Human behavior is a fundamental cause of the serious environmental problems that threaten the present and the future of life on Earth (Evans, 2019; Gifford and Sussman, 2012; Schultz and Kaiser, 2012; Steffen et al., 2015). Although the development of environmentally friendly technologies can help to ameliorate the burden we put on the planet, there is no purely technical solution to the current ecological crisis. Thus, understanding the factors and processes shaping people's pro-environmentalism (i.e. pro-environmental knowledge, attitudes and behaviors) is important to achieve a more sustainable future. Moreover, there is also an urgent need to promote changes in personal and collective ecological attitudes and behaviors that can ultimately lead to a sustainable society (Evans, 2019).

Higher education institutions can play a key role in sustainability provision because they can foster the values, behaviors and lifestyles required for a sustainable future (Dagiliute et al., 2018; Larrán et al., 2015). As such, universities have increasingly engaged in incorporating sustainability issues into their systems through a wide range of practices (Findler et al., 2019). These include interventions aimed at reducing universities' ecological footprint (Genta et al., 2019), the provision of campus gardens that offer hands-on learning opportunities (Cheang et al., 2017; Duram and Williams, 2015; Eugenio-Gozalbo et al., 2020) and improved environmental management strategies (Disterheft et al., 2012). However, the changes required to create more sustainable universities tend to occur at a slow rate and sustainability practices are often not fully integrated into higher education institutions (Leal Filho et al., 2019). One of the reasons for the often slow and only partial integration of sustainable practices at universities is the lack of awareness and interest that the educational community shows in environmental issues (Dagiliute et al., 2018; Larrán et al., 2015). Education for sustainable development (ESD) has been highlighted as a relevant tool to tackle this generalized lack of interest, as it can foster individuals' pro-environmentalism, including awareness about environmental issues, pro-environmental attitudes, values and behaviors (Arbuthnott, 2009; Michelsen and Fisher, 2017).

ESD refers to formal and informal learning activities focused on the preservation of natural resources (Arbuthnott, 2009). Importantly, research has shown that the impact of ESD on people's pro-environmentalism surpasses the effects of extrinsic motivators, such as incentives and punishments (De Young, 2000). Although research has examined the effectiveness of ESD on university students' pro-environmentalism (Findler et al., 2019), the strength of the evidence assessing ESD effects is constrained due to methodological limitations (Ssossé et al., 2021). These limitations include modest sample sizes, lack of preintervention baseline data (pre-tests) and failure to include a control or comparison group. Moreover, most studies have collected data immediately following the ESD intervention. Although this provides insights about the immediate effects of participation in the ESD intervention, the long-term effects of ESD at a higher educational level remain unknown. Furthermore, these methodological issues also make it difficult to provide specific guidelines that are necessary to successfully implement ESD programs at universities. As a result, there is a need for greater rigor in the design and execution of studies examining the impact of ESD interventions on university students' pro-environmentalism. This is especially relevant for Spanish universities, where institutions have stressed the urgency to more systematically include sustainability issues in higher education (Larrán et al., 2015). Given the above, we present the results of an ESD intervention aimed at increasing students' environmental knowledge, personal environmental norms and pro-environmental behaviors. The ESD intervention used in the present research was conducted in a Spanish university, evaluated through a quasi-experimental design, and collected data immediately following the intervention as well as one-year post-intervention. 


\subsection{Environmental knowledge, personal environmental norm and pro-environmental behaviors}

The ultimate aim of ESD is to foster pro-environmental behaviors (Arbuthnott, 2009), which are actions that contribute to the sustainability of nature (Schultz and Kaiser, 2012). In an attempt to engage people in pro-environmental actions, ESD has traditionally focused on providing factual information about environmental issues, as well as how and why we need to behave in an environmentally friendly way. The idea behind this approach is that individuals cannot be expected to display pro-environmental behavior if they do not know about the existence of environmental issues or the consequences that their actions have for the environment. Hence, environmental knowledge is thought to be a key component of ESD (Kaiser et al., 2008; Ssossé et al., 2021). Indeed, research indicates that because enhanced knowledge is positively linked to pro-environmental actions, ESD programs that focus on increasing environmental knowledge can yield more desirable outcomes. For example, Meinhold and Malkus (2005) found that adolescents who reported more (vs less) environmental knowledge also indicated a higher frequency of conducting proenvironmental behaviors. Likewise, Morren et al. (2021) found that knowledge about the effects of what we eat on the environment predicts the sustainability of our diets. These data revealed that procedural information (i.e. how to carry out an action) stimulated behavioral change, while declarative information (i.e. fact about a certain topic) did not. Conversely, Geiger et al. (2019) found that declarative knowledge on a wide range of environmental topics does predict pro-environmental behaviors. These researchers argued that environmental knowledge should not be measured indirectly (e.g. self-concepts of one's own knowledge), but rather directly, through, for instance, performance on a knowledge test. Taken together, although the relationship between knowledge and pro-environmental action is well-established, it is generally moderate to weak (Braun and Dierkes, 2019; Otto and Pensini, 2017; Trémoliere and Djeriouat, 2021). Thus, ESD has gradually shifted attention to other determinants of people's pro-environmental actions. One of these factors is personal environmental norms.

Norms have successfully been used to explain a wide variety of behaviors, including proenvironmental actions (ThØgersen, 2006). Personal norms refer to a feeling of moral obligation to behave in a certain way, which in accordance with norm-activation theory (Schwartz, 1977), leads to the performance of certain behaviors. Of interest to the current study, acting in favor of the environment has long been considered a moral issue. In fact, previous findings support a direct link between personal environmental norms and proenvironmental behaviors such as recycling (ThØgersen, 1996) and the use of public means of transportation (Bamberg et al, 2007). For example, Collado et al. (2019) found that personal norms significantly predicted adolescents' pro-environmental behaviors, mediating the effect that other factors, such as social norms, had on the frequency of conducting proenvironmental actions. Similar results were found by Matthies et al. (2012) in a sample of children. Importantly, prior research suggests that participation in an ESD intervention may increase a personal sense of moral obligation to protect the environment. For example, Hahn and Garrett (2017) conducted an ESD intervention with preschool children, which revealed that taking the perspective of someone whose environment had been polluted and destroyed led to a stronger sense of morality toward the environment and hence, to condemning environmentally harmful actions. Following a similar approach, Collado et al. (2021) conducted an ESD intervention with primary school children that investigated whether learning about animals and their relationship to humans (i.e. increasing environmental knowledge) could lead to a stronger sense of moral obligation to treat animals fairly. The data revealed that participation in the ESD intervention led children to perceive actions that
Sustainable development intervention 
hurt animals as something that is wrong and, therefore, should not be done. Although numerous studies have investigated the efficacy of ESD interventions among adolescents and children, to this point, relatively few attempts have been made to examine the role of ESD interventions on university students' personal environmental norms (Murray et al., 2013).

Bearing this in mind, the present research concurs with previous calls for research suggesting that ESD should move beyond its traditional grounds and consider relatively unexplored factors that can be linked to pro-environmental behaviors (Arbuthnott, 2009). As just noted, this topic is especially relevant within the context of higher education (e.g. universities) because most ESD interventions have been conducted in the context of primary education (Ssossé et al., 2021).

\section{Methodology}

\subsection{Study design}

The present study examined the impact of participation in an ESD intervention on university students' environmental knowledge, personal norms and pro-environmental behaviors. Given that ESD is still seen as innovative in higher education (Ely, 2018; Leal Filho et al., 2019), particularly in Spain (Larrán et al., 2015), our ESD was designed as an educational innovation project. Our study also sought to address some of the methodological weaknesses found in previous studies in several ways. First, to provide a baseline measure of comparison against which we could then evaluate the efficacy of the ESD intervention, we included a control group that did not take part in the ESD intervention. This allowed us to directly examine and compare the impact that participating in an ESD intervention had on university students' pro-environmentalism (i.e. experimental group), compared to those who did not participate in the ESD intervention (i.e. control group). Second, we measured changes in our key dependent variables at two-time points (i.e. immediately following the intervention and one-year post-intervention) to examine the durability of the effects engendered by our ESD intervention. Our prediction was that participants in the experimental group should report increases in their environmental knowledge, personal environmental norms and their self-reported pro-environmental behaviors when comparing pre-intervention (T0) with post-intervention (T1) scores on each of these measures. Conversely, no changes were expected to occur in the control group (H1). Importantly, we also expected that participants in the experimental group should benefit from the long-term effects of the ESD intervention, such that their scores on environmental knowledge, personal environmental norms and self-reported pro-environmental behavior at T2 should remain significantly higher than their scores at T0 (H2).

\subsection{Description of the intervention}

The ESD intervention was designed considering the need to move from transmissive pedagogies (i.e. passing knowledge) to more transformative methods that boost individuals' personal engagement with sustainability (Murray et al., 2013). In particular, we considered the relevance of experiential learning in ESD interventions organized at universities for knowledge and competence acquisition (Ely, 2018). The intervention was designed by a group of interdisciplinary professionals who were in charge of ensuring the sustainability of the campus where the intervention took place. Its ultimate aim was to enhance students' personal environmental stewardship in terms of knowledge about the sustainable development goals (SDG) and related issues, personal environmental norms and proenvironmental behaviors. Although SDG covers different global challenges, including poverty, inequality, climate change, environmental degradation, peace and justice, the 
intervention focused on sustainability issues specifically linked to preserving the environment (e.g. responsible consumption and production, climate action, affordable and clean energy).

The ESD intervention consisted of 10 2-h-long workshops, one of which took place every two weeks, from October 2018 until March 2019. Each workshop was led by one or two experts on a certain topic (e.g. waste management) and consisted of a short introduction to the topic followed by one or more practical exercises (e.g. interpretation of students' own electricity bill, role-playing, designing an ESD campaign for their campus). The practical exercises were conducted in groups of 4-5 people and designed to foster students' reflexive thinking, sharing perspectives and learning through their peers. For instance, in the workshop focused on electricity, students were asked to bring their electricity bills to the class. They first received a short lecture about where electricity comes from, the implications that different electricity sources have for the environment, how electricity bills are calculated and ways through which electricity can be saved. Next, students were asked to reflect on their personal electricity bills and then share ideas with their group regarding how to be more pro-environmental in terms of saving both energy and money. As another example, during the role-playing activities, two groups of students were formed: pro- and anti-environmental. A jury formed by two of the ESD coordinators told the students that the campus had some funds that could be allocated to a specific sustainability action (e.g. recycling on campus). The pro-environmental group had to convince the jury that the money should go to their cause (e.g. increasing the number of recycling bins on campus), whereas the anti-environmental group needed to convince the jury that the environmental cause was a waste of money and that the funds would be better used elsewhere (e.g. a reading club). The jury considered the underlying logic of each presentation and then decided where the funds would be allocated.

In addition to the above, participants had to work on a final project titled "Implementing what we have learned." It consisted of using the knowledge and skills they had acquired through the workshops to design an intervention proposal geared toward creating a more sustainable university campus. The final project could be delivered in any format (e.g. video, poster and sculpture) and should be accompanied by a short essay describing the proposal. The university organizes an annual Environment Week, at which the proposals were later exhibited and explained to members of the university community.

\subsection{Participants and procedure}

The study took place at the Faculty of Social and Human Sciences of the University of Zaragoza (Teruel Campus, Spain). Participants were predominantly undergraduates enrolled in different courses, including Primary School Education (57.1\%), Psychology $(22.4 \%)$, Nursey School Education (15.3\%) and Business Management (2\%). In total, $3 \%$ of the participants were Master's students. Students in the aforementioned Faculty were encouraged to join the ESD intervention through different media (e.g. their own teachers, advertisements on the university website and social media). Those students who decided to join the intervention were asked to email the intervention coordinator and were then enrolled, thus becoming part of the experimental group (i.e. participants were not randomly assigned to the experimental and control groups). The intervention was formally embedded as part of the Faculty's extra-curricular activities offer. Participation was free of charge and students who successfully completed the ESD intervention received one European Credit Transfer and Accumulation System (ECTS) credit. A call was also made for students who did not enroll in the intervention, which asked them to complete the questionnaires at T0
Sustainable development intervention 
and T1 (i.e. control group). The experimental group consisted of 120 students $\left(M_{\text {age }}=20.23\right.$; $S D=1.84)$, whereas the control group had 137 participants $\left(M_{\text {age }}=20.34 ; S D=1.70\right)$.

Data were collected through an online platform, through which students provided informed consent before participating in the intervention. We only report data from those students who completed the ESD intervention and both questionnaires (pre and postintervention). About $18 \%$ of the students who completed the questionnaire at T0 either dropped out of the intervention, missed at least one workshop and/or did not complete the questionnaire at T1. Data from these students are not included in our analyses. Because we were also interested in examining the long-term effects of the intervention, participants were contacted one year after the intervention finished (March 2020) and asked to complete the questionnaires one more time (T2). In total, 49 students from the experimental group completed the questionnaire at T2 and 49 from the control group. Overall, the dropout rate was $61.87 \%(n=159)$. Thus, our final sample size included data on all measures from 98 participants.

\subsection{Measures}

2.4.1 Environmental knowledge. This variable was operationalized using a 10-item multiplechoice questionnaire. It covers each of the topics included in the ESD intervention. The content validity of the instrument was established by a group of environmental researchers and professionals involved in the organization of the ESD intervention, together with the professionals in charge of each workshop. It was pilot-tested for clarity and comprehension using students from a different campus. This questionnaire is shown in Appendix 1. Final scores were computed by dividing the total number of correct answers by 2 , which allowed for scores ranging between 0 and 5 . Higher scores reflect more environmental knowledge.

2.4.2 Self-reported pro-environmental behaviors. This measure was comprising eight items previously used in studies with Spanish students (Collado et al., 2019). Participants indicated the frequency of conducting each behavior on a five-point scale, from 1 (never) to 5 (always). The behaviors included were I separate paper and cardboard from the rest of the waste, I separate glass from the rest of the trash, I separate plastic from the rest of the trash, I make an effort to not waste electricity, I make an effort to not waste water, I remind my friends to collect our trash after a picnic, I participate in initiatives to protect the environment and I spend time in natural areas. The internal consistency of this measure was good at each of the three-time points in which data were collected (T0 $\alpha=0.832$; T1 $\alpha=$ 0.829; T2 $\alpha=0.852$ ). Higher scores reflect a greater frequency of performing proenvironmental behaviors.

2.4.3 Personal environmental norms. Participants reported whether they felt morally obliged to conduct each of the eight behaviors described above. For instance, "because of my own values/principles, I separate glass from the rest of the trash" The internal consistency of this measure was high at each of the three-time points: T0 $\alpha=0.915$; T1 $\alpha=0.917$; T2 $\alpha=$ 0.894. Higher scores reflect an increased perception of moral obligation to perform the behaviors described in the self-reported pro-environmental behavior measure.

\subsection{Data analysis}

The data were analyzed with linear mixed-effects models using the $l m 4$ package (version Ime4_1.1-13; Bates et al., 2015) for R statistical software (version 4.1.0; R Development Core Team, 2021). Three different models were fitted, one for each dependent measure: environmental knowledge, self-reported pro-environmental behaviors and personal environmental norm. For each model, Condition (Control vs Experimental), Time (T0 vs T1 vs T2) and their interaction term were entered as fixed effects. Condition and Time were 
dummy coded, Control group and Time 0 were the baselines. Random intercepts for participants were included in the random part of the models [i.e. Dependent measure $\sim$ Time $\times$ Condition $+(1 \mid$ Participant $)]$. Tables for random effects and estimates of fixed effects for the three models are presented in Appendix 2.

\section{Results}

Descriptive statistics for our outcome measures at T0, T1 and T2 for the experimental and control groups are provided in Table 1.

\subsection{Environmental knowledge}

The model for environmental knowledge showed no significant interaction effects between Time (T0) and Condition (Experimental), $\mathrm{b}=0.08,95 \%$ CI $[-0.20-0.36], t=0.58$. Hence, environmental knowledge was similar in both groups at baseline. We found statistically significant interactions between Time (T1) and Condition (Experimental), b = 1.04, 95\% CI [0.65 - 1.43], $t=5.19$ and also between Time (T2) and Condition (Experimental), $\mathrm{b}=0.74$, $95 \%$ CI $[0.35-1.14], t=3.72$. Participants in the experimental group showed higher environmental knowledge at $\mathrm{T} 1, \mathrm{~b}=1.12,95 \% \mathrm{CI}[0.84-1.40], t=7.92$ and also at $\mathrm{T} 2, \mathrm{~b}=$ $0.83,95 \% \mathrm{CI}[0.55-1.10], t=5.84$, than participants in the control condition, which leads the interaction effect (Figure 1). This effect was not only larger at T1 but also sizable at T2.

\subsection{Personal environmental norms}

The model for the personal environmental norms showed no significant interaction effect between Time (T0) and Condition (Experimental), $\mathrm{b}=-0.01,95 \% \mathrm{CI}[-0.30-0.28], t=$ -0.06 , indicanting that partipants' feelings of personal obligation to protect the environment was similar across groups. Statistically significant interactions were found between Time (T1) and Condition (Experimental), $\mathrm{b}=0.53,95 \% \mathrm{CI}[0.21-0.86], t=3.22$ and also between Time (T2) and Condition (Experimental), $\mathrm{b}=0.34,95 \% \mathrm{CI}[0.02-0.67], t=2.06$. Participants in the experimental group reported a stronger personal environmental norms at $\mathrm{T} 1, \mathrm{~b}=0.52$, $95 \% \mathrm{CI}[0.24-0.81], t=3.56$ and also at $\mathrm{T} 2, \mathrm{~b}=0.33,95 \% \mathrm{CI}[0.04-0.62], t=2.25$, than participants in the control condition, which leads to the interaction effect (Figure 2). This effect was not only stronger at $\mathrm{T} 1$ but also sizable at $\mathrm{T} 2$.

\subsection{Self-reported pro-environmental behaviors}

We found no significant differences in self-reported pro-environmental behaviors at T0 across groups, $\mathrm{b}=-0.03,95 \% \mathrm{CI}[-0.30--0.24], t=-0.24$, indicating that participants'

\begin{tabular}{llllllll}
\hline \multirow{2}{*}{ Measure } & Condition & $M$ & \multicolumn{2}{c}{ Time 0 } & \multicolumn{2}{c}{ Time 1 } & \multicolumn{2}{c}{ Time 2 } \\
\hline Knowledge & Experimental & 1.82 & 0.66 & 3.03 & 0.81 & 2.77 & 0.88 \\
& Control & 1.73 & 0.57 & 1.91 & 0.74 & 1.94 & 0.52 \\
Norm & Experimental & 3.72 & 0.61 & 4.31 & 0.51 & 4.06 & 0.65 \\
& Control & 3.73 & 0.98 & 3.78 & 0.91 & 3.73 & 0.65 \\
Behaviors & Experimental & 3.37 & 0.72 & 4.23 & 0.25 & 4.03 & 0.51 \\
& Control & 3.40 & 0.93 & 3.52 & 0.75 & 3.37 & 0.72
\end{tabular}

Notes: Knowledge = environmental knowledge, Norm = environmental personal norms, Behaviors $=$ selfreported pro-environmental behaviors
Sustainable development intervention

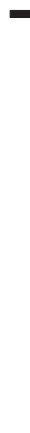




\section{IJSHE}

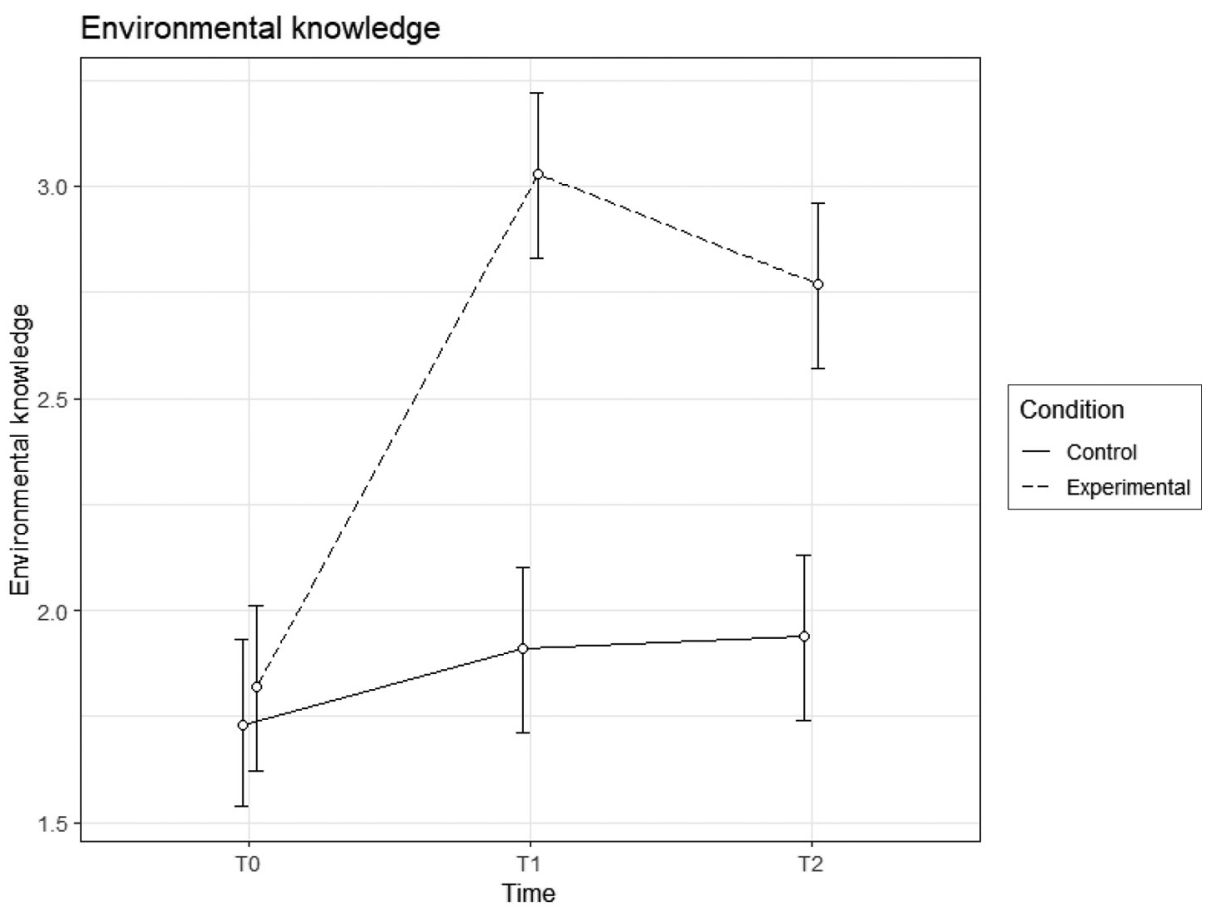

Figure 1.

Model estimates for environmental knowledge at times 0 , 1 and 2 as a function of condition: control versus experimental. Error bars represent $95 \%$ Cl's

pro-environmental behaviors were similar at baseline. Statistically significant interactions were found between Time (T1) and Condition (Experimental), $\mathrm{b}=0.83,95 \%$ CI [0.54 - 1.12], $t=5.63$ and also between Time (T2) and Condition (Experimental), $\mathrm{b}=0.69,95 \%$ CI $[0.40-$ 0.98], $t=4.70$. Participants in the experimental group reported conducting proenvironmental behaviors more frequently than those in the control group, both at $\mathrm{T} 1, \mathrm{~b}=$ $0.80,95 \% \mathrm{CI}[0.53-1.07], t=5.86$ and at T2, $\mathrm{b}=0.66,95 \% \mathrm{CI}[0.39-0.93], t=4.85$, which leads to the interaction effect (Figure 3). The effect was not only larger at T1 but also sizable at T2.

\section{Discussion}

ESD is an essential tool in the pathway toward a more sustainable society (UNESCO, 2018). However, the implementation of ESD practices in educational settings, especially in higher education, is still scarce (Leal Filho et al., 2019). One of the reasons for this is a lack of evidence regarding the effectiveness of ESD. Hence, a call has recently been made for experiments that will empirically test whether and to what extent ESD interventions may influence pro-environmentalism attitudes and behaviors (Ssossé et al., 2021). Considering this call, the present study sought to compare the effects of an ESD intervention on university students' environmental knowledge, personal environmental norms and proenvironmental behaviors, against a control group who did not participate in the intervention and furthermore, to examine the durability of these effects over a period of one year.

Our data indicated that students in the experimental and control groups reported similar levels of knowledge, personal environmental norms and pro-environmental behaviors prior to the intervention (T0). In line with previous studies, at baseline, students' sense of moral 


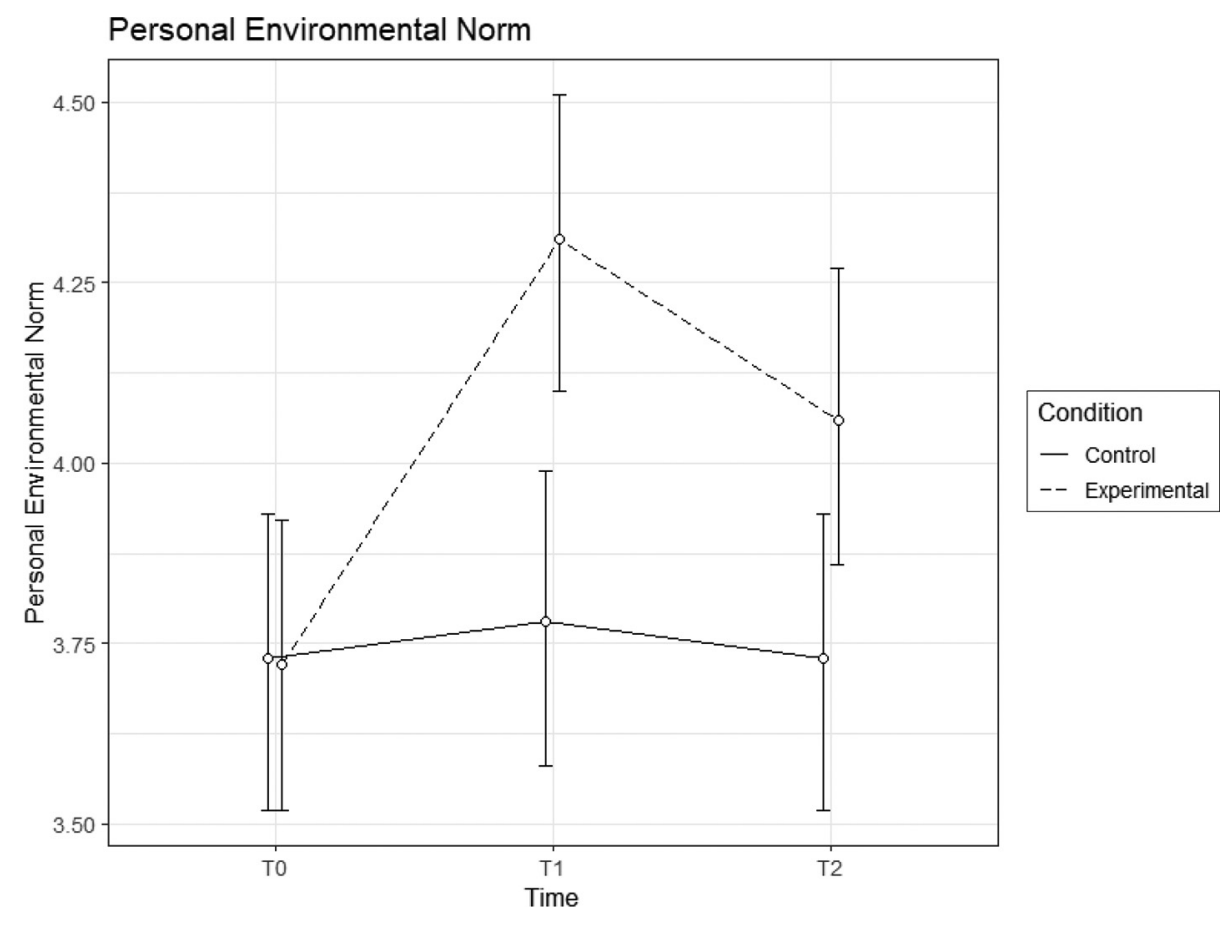

Sustainable development intervention

Figure 2.

Model estimates for personal environmental norm at times 0,1 and 2 as a function of condition: control versus experimental. Error bars represent $95 \%$ Cl's

obligation to protect the environment (i.e. personal norms) and self-reported proenvironmental behaviors were moderate (Collado et al., 2019; Harland et al., 1999; Matthies et al., 2012). This might reflect the fact that young adults tend to be concerned with environmental protection (Wallis and Loy, 2021), which might be linked to a need for compliance with social norms related to pro-environmental behaviors. In Western countries, it is common to receive information about the seriousness of environmental issues, the urgency of taking care of the environment and daily actions individuals can conduct to preserve the environment through various media outlets, such as television, school and social media. University students might perceive the adherence to a sustainable lifestyle as something most people do (i.e. descriptive norm) and thus try to align with the majority. Another plausible reason is that university students would have probably received some kind of environmental education in their primary school years (Wals, 2012), the effects of which might last until young adulthood. In contrast with personal norms and behaviors, students' environmental knowledge at T0 was relatively low in both experimental and control groups. This is somewhat unexpected as university students' environmental knowledge tends to be moderate (Sahin et al., 2013; Sousa et al., 2020). One reason for students' low baseline knowledge may be that, compared to previous studies measuring selfreported environmental knowledge (Duerden and Witt, 2010), we recorded knowledge using an objective measure. Using an objective (vs subjective) measure of knowledge, removed any biases associated with self-reporting one's knowledge about a topic, which might have biased the findings of previous studies. Moreover, the items used to register environmental knowledge were quite specific and, compared to more general knowledge about the environment, specific facts might be more difficult to acquire (Geiger et al., 2019). 


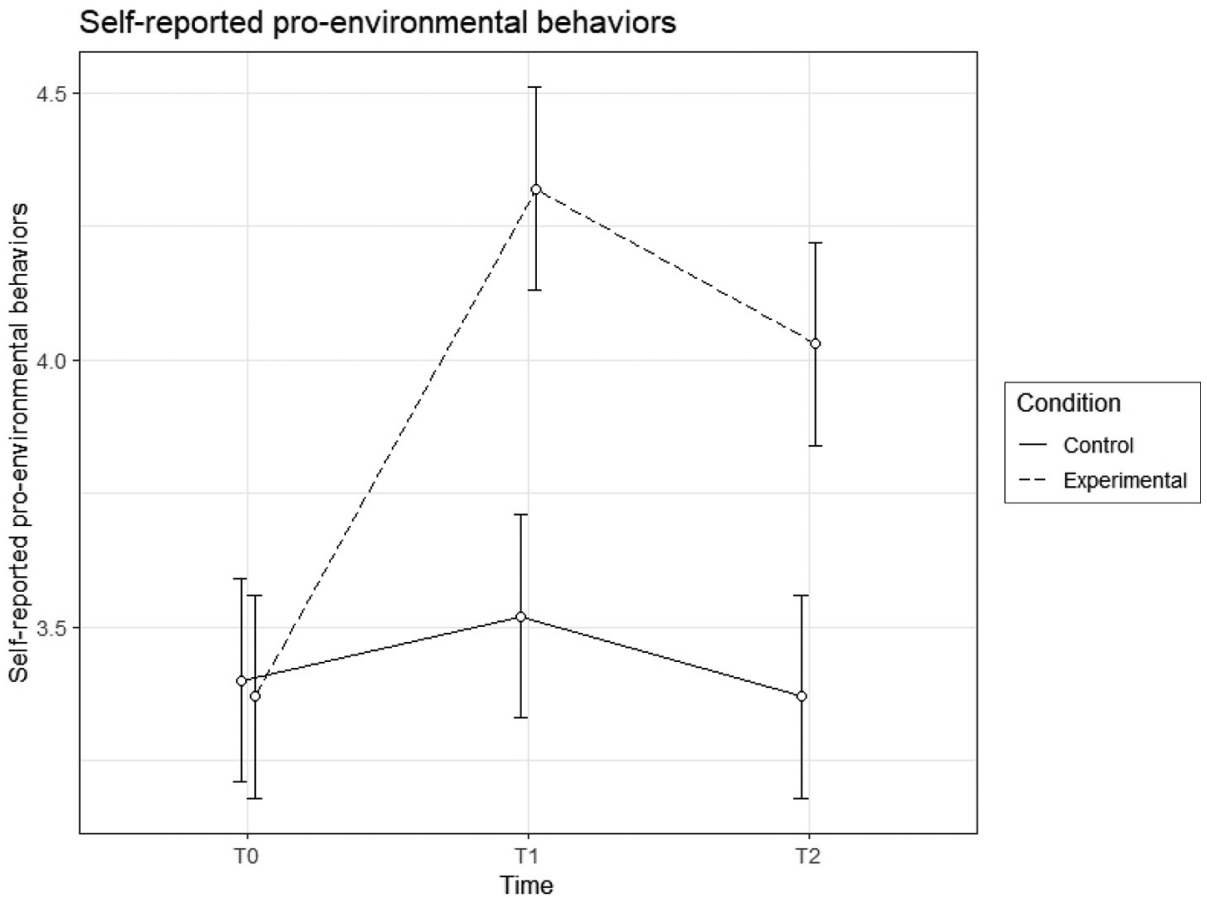

Figure 3.

Model estimates for self-reported proenvironmental behaviors at times 0 , 1 and 2 as a function of condition: control versus experimental. Error bars represent 95\% Cl's

In line with $H 1$, participation in an ESD intervention increased students' environmental knowledge, personal environmental norms and pro-environmental behaviors. Conversely, no significant differences on any of these variables emerged across time-points for participants in the control group. These results are also in accordance with previous studies showing that ESD interventions in higher education institutions can foster sensitivity to others (including sensitivity toward the environment), to the power of the community (Seeberg and Minick, 2012), increase awareness about climate change and abilities to solve complex environmental issues (Paschall and Wüstenhagen, 2012) and pro-environmental behaviors (Cheung et al., 2018). Specifically, similar to Murray et al. (2013), we found that participation in the ESD intervention increased students' awareness and knowledge about environmental issues, as well as their commitment to pro-environmental behaviors. Through qualitative follow-up interviews conducted four months after the intervention, Murray et al. (2013) found that students' personal engagement with sustainability also had increased and remained months after the intervention finished. Building on these findings, our results show that students' sense of personal obligation to protect the environment also increased after the intervention (i.e. personal environmental norms). This result is especially relevant because it shows that participation in an ESD intervention not only increased students' knowledge and awareness about environmental issues but can also provoke learners to reflect on their own personal values, which ultimately may lead to personal change (Masson and Otto, 2021). Also remarkable is the fact that improvements in students' environmental knowledge, personal environmental norms and pro-environmental behavior persisted over the course of a year, which is in line with $H 2$. This speaks to the effectiveness of ESD to promote long-lasting awareness about environmental issues and personal 
engagement with sustainable practices. No increases were found on any of these measures over time for participants in the control group, which also provides supporting evidence regarding the effectiveness of the intervention (i.e. improvements in the experimental group are due to participation in the ESD intervention).

Considering the positive results of the intervention as noted above, the present study has relevant implications for practice and society. Implementing an ESD intervention, like the one proposed in this study, through workshops, seminars, role-playing activities and practical exercises can be a useful educational tool in higher instructional contexts, as these techniques have been proven to enhance environmental awareness, personal engagement with sustainability issues and pro-environmental actions among students.

An increasing number of universities consider sustainability as a priority (Leal Filho et al., 2019), including the university in which the current study was conducted. However, the lack of improvement found in the control group over the course of a year suggests that while university leaders adhere to sustainable practices (e.g. environmental management strategies), these do not foster individuals' personal engagement with sustainability within the university community. Until higher education institutions go through the transformative process required to integrate sustainability into their systems (Larrán et al., 2015), ESD interventions like the one described here are an effective way to enhance sustainability among students. This intervention can be easily replicated in other higher education institutions, given that it is a transversal and extracurricular activity that is relatively easy to implement. As shown, students' adherence to the intervention can be fostered by offering ECTS credits; however, other strategies, such as the possibility of obtaining a certifying diploma, might also be useful. It should also be noted that our data suggested students' levels of pro-environmentalism diminished when comparing the effects of the intervention at T1 (post-intervention) with measures obtained at T2, one year after the intervention. Bearing this in mind, a booster session designed to refresh students' knowledge, skills and values about sustainability is advisable. Finally, we would like to highlight the low human and material costs of implementing an intervention like this, as well as the transformative potential for the students and positive downstream consequences for society.

Our study has several limitations that provide a foundation for future lines of research. First, students in the experimental group voluntarily joined the intervention, thus participants were not randomly assigned to the experimental conditions. Nevertheless, participants in both groups showed similar levels of pro-environmentalism at baseline, ruling out the possibility that students who joined the intervention were significantly more engaged with sustainability than those in the control group. Second, pro-environmental behavior was self-reported by participants, which could have biased the results. Actual behavioral measures have successfully been used at universities (Cheung et al., 2018) and are encouraged in future studies to obtain a more reliable estimation of students' pro-environmental practices. Third, the intervention focused on environmental issues, which proved effective at enhancing personal pro-environmental engagement. However, sustainability also integrates other areas such as quality education, gender equality, reduced inequality, decent work and economic growth. University students should also receive training in these areas through ESD interventions, and the effectiveness of these interventions should be examined, preferably through studies that allow causal claims regarding the effects of an intervention.

\section{Conclusion}

Innovation in higher education is key in the promotion of a more sustainable society (Leal Filho et al., 2019). However, the bulk of evidence within this literature that supports the impact of participation in innovative ESD initiatives is impaired due to methodological issues in prior 
studies. This study examined the effectiveness of an ESD intervention at a university level on students' pro-environmentalism following a quasi-experimental design. The results showed that students who participated in this ESD intervention improved their knowledge about environmental issues and their environmental personal norms and also reported behaving in more pro-environmental ways compared to those who did not participate in this intervention. These results are promising, as the effects of the intervention were also visible a year after the intervention, highlighting the relevance of applying ESD interventions in higher educational settings to increase pro-environmentalism in new generations.

\section{References}

Arbuthnott, K. (2009), "Education for sustainable development beyond attitude change", International Journal of Sustainability in Higher Education, Vol. 10 No. 2, pp. 152-163, doi: 10.1108/ 14676370910945954.

Bamberg, S., Hunecke, M. and Blobaum, A. (2007), "Social context, personal norms and the use of public transportation: two field studies", Journal of Environmental Psychology, Vol. 27 No. 3, pp. 190-203, doi: 10.1016/j.jenvp.2007.04.001.

Bates, D., Maechler, M., Bolker, B. and Walker, S. (2015), "Fitting linear mixed-effects models using lme4", Journal of Statistical Software, Vol. 67 No. 1, pp. 1-48, doi: 10.18637/jss.v067.i01.

Braun, T. and Dierkes, P. (2019), "Evaluating three dimensions of environmental knowledge and their impact on behavior", Research in Science Education, Vol. 49 No. 5, pp. 1347-1365, doi: 10.1007/ s11165-017-9658-7.

Cheang, C.C., So, W.M.W., Zhan, Y. and Tsoi, K.H. (2017), "Education for sustainability using a campus eco-garden as a learning environment", International Journal of Sustainability in Higher Education, Vol. 18 No. 2, pp. 242-262, doi: 10.1108/IJSHE-10-2015-0174.

Cheung, T.Y., Fok, L., Cheang, C.-C., Yeung, C.H., Winnie So, W.-M. and Chow, C.-F. (2018), "University halls plastics recycling: a blended intervention study", International Journal of Sustainability in Higher Education, Vol. 19 No. 6, pp. 1038-1052, doi: 10.1108/IJSHE-10-2017-0175.

Collado, S., Rodríguez-Rey, R. and Sorrel, M.A. (2021), "Does beauty matter? The effect of perceived attractiveness on children's moral judgments of harmful actions against animals", Environment and Behavior, Advance online publication, doi: 10.1177/00139165211014626.

Collado, S., Staats, H. and Sancho, P. (2019), "Normative influences on adolescent's self-reported proenvironmental behaviors: the role of parents and friends", Environment and Behavior, Vol. 51 No. 3, pp. 288-314, doi: 10.1177\%2F0013916517744591.

Dagiliute, R., Liobikiene, G. and Minelgaite, A. (2018), "Sustainability at universities: students' perception from green and non-green universities", Journal of Cleaner Production, Vol. 181, pp. 473-482, doi: 10.1016/j.jclepro.2018.01.213.

De Young, R. (2000), "New ways to promote proenvironmental behavior: expanding and evaluating motives for environmentally responsible behavior", Journal of Social Issues, Vol. 56 No. 3, pp. 509-526, doi: 10.1111/0022-4537.00181.

Disterheft, A., Ferreira da Silva Caeiro, S.S., Ramos, M.R. and de Miranda Azeiteiro, U.M. (2012), "Environmental management systems (EMS) implementation processes and practices in European higher education institutions - top - down versus participatory approaches", Journal of Cleaner Production, Vol. 31, pp. 80-90.

Duerden, M.D. and Witt, P.A. (2010), "The impact of direct and indirect experiences on the development of environmental knowledge, attitudes, and behavior", Journal of Environmental Psychology, Vol. 30 No. 4, pp. 379-392, doi: 10.1016/j.jenvp.2010.03.007.

Duram, L.A. and Williams, L.L. (2015), "Growing a student organic garden within the context of university sustainability initiatives", International Journal of Sustainability in Higher Education, Vol. 16 No. 1, pp. 3-15, doi: 10.1108/IJSHE-03-2013-0026. 
Ely, A.V. (2018), "Experiential learning in 'innovation for sustainability': an evaluation of teaching and learning activities (TLAs) in an international masters course", International Journal of Sustainability in Higher Education, Vol. 19 No. 7, pp. 1204-1219, doi: 10.1108/IJSHE-08-2017-0141.

Eugenio-Gozalbo, M., Ramos-Truchero, G. and Suárez-López, R. (2020), "University gardens for sustainable citizenship: assessing the impacts of garden-based learning on environmental and food education at Spanish higher education", International Journal of Sustainability in Higher Education, Vol. 22 No. 3, pp. 516-534, doi: 10.1108/IJSHE-06-2020-0208.

Evans, G.W. (2019), "Projected behavioral impacts of global climate change", Annual Review of Psychology, Vol. 70 No. 1, pp. 449-474, doi: 10.1146/annurev-psych-010418-103023.

Findler, F., Schönherr, N., Lozano, R., Reider, D. and Martinuzzi, A. (2019), "The impacts of higher education institutions on sustainable development: a review and conceptualization", International Journal of Sustainability in Higher Education, Vol. 20 No. 1, pp. 23-38, doi: 10.1108/IJSHE-07-2017-0114.

Geiger, S.M., Geiger, M. and Wilhelm, O. (2019), "Environment-specific vs general knowledge and their role in pro-environmental behavior", Frontiers in Psychology, Vol. 10, p. 718, doi: 10.3389/fpsyg.2019.00718.

Genta, C., Favaro, S., Sonetti, G., Barioglio, C. and Lombardi, P. (2019), "Envisioning green solutions for reducing the ecological footprint of university campus", International Journal of Sustainability in Higher Education, Vol. 20 No. 3, pp. 423-440, doi: 10.1108/IJSHE-01-2019-0039.

Gifford, R. and Sussman, R. (2012), "Environmental attitudes", in Clayton, S. (Ed.), The Oxford Handbook of Environmental and Conservation Psychology, Oxford University Press, pp. 92-114.

Hahn, E.R. and Garrett, M.K. (2017), "Preschoolers' moral judgments of environmental harm and the influence of perspective taking", Journal of Environmental Psychology, Vol. 53, pp. 11-19, doi: 10.1016/j.jenvp.2017.05.004.

Harland, P., Staats, H. and Wilke, M. (1999), "Explaining pro-environmental intention and behavior by personal norms and the theory of planned behavior", Journal of Applied Social Psychology, Vol. 29 No. 12, pp. 2505-2528, doi: 10.1111/j.1559-1816.1999.tb00123.x.

Kaiser, F.G., Roczen, N. and Bogner, F.X. (2008), "Competence formation in environmental education: advancing ecology-specific rather than general abilities”, Umweltpsychologie, Vol. 12, pp. 56-70, doi: https://doi.org/10.5167/uzh-9249.

Larrán, M., Herrera, J., Calzado, Y. and Andrades, F.J. (2015), “An approach to the implementation of sustainability practices in Spanish universities", Journal of Cleaner Production, Vol. 106, pp. 34-44, doi: 10.1016/j.jclepro.2014.07.035.

Leal Filho, W., Emblen-Perry, K., Molthan-Hill, P., Mifsud, M., Verhoef, L., Miranda, U., Bacelar-Nicolau, P., Olim de Sousa, L., Castro, P., Baynaghi, A., Boddy, J., Lange, A., Frankenberger, F. and Price, E. (2019), "Implementing innovation on environmental sustainability at universities around the world", Sustainability, Vol. 11 No. 14, p. 3807, doi: 10.3390/su11143807.

Masson, T. and Otto, S. (2021), "Explaining the difference between the predictive power of value orientations and self-determined motivation for proenvironmental behavior", Journal of Environmental Psychology, Vol. 73, p. 101555, doi: 10.1016/j.jenvp.2021.101555.

Matthies, E., Selge, S. and Klockner, C. (2012), "The role of parental behavior for the development of behavior specific environmental norms: the example of recycling and re-use behavior", Journal of Environmental Psychology, Vol. 32 No. 3, pp. 277-284, doi: 10.1016/j.jenvp.2012.04.003.

Meinhold, J. and Malkus, A.J. (2005), "Adolescent environmental behavior. Can knowledge, attitudes, and self-efficacy make a difference?”, Environment and Behavior, Vol. 37 No. 4, pp. 511-532, doi: $10.1177 / 0013916504269665$.

Michelsen, G. and Fisher, D. (2017), "Sustainability and education”, in Hau, M.V. and Kuhnke, C. (Eds), Sustainable Development Policy: A European Perspective, Routledge, pp. 135-158.

Morren, M., Mol, J.M., Blasch, J. and Malek, Z. (2021), "Changing diets - testing the impact of knowledge and information nudges on sustainable dietary choices", Journal of Environmental Psychology, Vol. 75, p. 101610. 
Murray, P., Goodhew, J. and Murray, S. (2013), "The heart of ESD: personally engaging learners with sustainability", Environmental Education Research, Vol. 20 No. 5, pp. 718-734, doi: 10.1080/ 13504622.2013.836623.

Otto, S. and Pensini, P. (2017), "Nature-based environmental education of children: environmental knowledge and connectedness to nature, together, are related to ecological behaviour", Global Environmental Change, Vol. 47, pp. 88-94, doi: 10.1016/j.gloenvcha.2017.09.009.

Paschall, M. and Wüstenhagen, R. (2012), "More than a game: learning about climate change through role-play", Journal of Management Education, Vol. 36 No. 4, pp. 510-543, doi: 10.1177/ 1052562911411156 .

R Development Core Team (2021), "R: a language and environment for statistical computing", version 4.1.0. $\mathrm{R}$ foundation for statistical computing, Vienna, ISBN 3-900051-07-0, available at: www.Rproject.org/

Sahin, H., Kiliç, I. and Erkal, S. (2013), "An analysis of the environmental knowledge and attitudes of university students", The International Journal of Interdisciplinary Environmental Studies, Vol. 7 No. 1, pp. 1-11, doi: https://doi.org/10.18848/2329-1621/CGP/v07i01/63976.

Schultz, P.W. and Kaiser, F. (2012), "Promoting pro-environmental behavior", in Clayton, S. (Ed.), The Oxford Handbook of Environmental and Conservation Psychology, Oxford University Press, pp. 556-580.

Schwartz, S.H. (1977), "Normative influences on altruism", in Berkowitz, L. (Ed.), Advances in Experimental Social Psychology, Academic Press, pp. 221-279.

Seeberg, V. and Minick, T. (2012), "Enhancing cross-cultural competence in multicultural teacher education: transformation in global learning", International Journal of Multicultural Education, Vol. 14 No. 3, pp. 1-22, doi: 10.18251/ijme.v14i3.569.

Sousa, S., Correia, E., Leite, J. and Viseu, C. (2020), "Environmental knowledge, attitudes and behavior of higher education students: a case study in Portugal", International Research in Geographical and Environmental Education, Vol. 30 No. 4, pp. 1-18, doi: 10.1080/ 10382046.2020.1838122.

Ssossé, Q., Wagner, J. and Hopper, C. (2021), “Assessing the impact of EDS: methods, challenges, results", Sustainability, Vol. 13 No. 5, p. 2854, doi: 10.3390/su13052854.

Steffen, W., Richardson, K., Rockström, J., Cornell, S.E., Fetzer, I., Bennett, E.M., Biggs, R., Carpenter, S.R., De Vries, W., De Wit, C.A. and Folke, C. (2015), "Planetary boundaries: guiding human development on a changing planet”, Science, Vol. 347 No. 6223, pp. 736-745, doi: 10.1126/science.1259855.

Thøgersen, J. (1996), "Recycling and morality: a critical review of the literature", Environment and Behavior, Vol. 28 No. 4, pp. 536-558, doi: 10.1177/0013916596284006.

Thøgersen, J. (2006), "Norms for environmentally responsible behavior: an extended taxonomy", Journal of Environmental Psychology, Vol. 26 No. 4, pp. 247-261, doi: 10.1016/j.jenvp.2006.09.004.

Trémoliere, B. and Djeriouat, H. (2021), "Exploring the roles of analytic cognitive style, climate science literacy, illusion of knowledge, and political orientation in climate change skepticism", Journal of Environmental Psychology, Vol. 74, doi: 10.1016/j.jenvp.2021.101561.

UNESCO (2018), Issues and Trends of Education for Sustainable Development, UNESCO, Paris.

Wallis, H. and Loy, L.S. (2021), "What drives pro-environmental activism of young people? A survey study on the Fridays for future movement”, Journal of Environmental Psychology, Vol. 74, p. 101581, doi: 10.1016/j.jenvp.2021.101581.

Wals, A.E.J. (2012), "Learning our way out of unsustainability: the role of environmental education", in Clayton, S. (Ed.), The Oxford Handbook of Environmental and Conservation Psychology, Oxford University Press, pp. 628-644, doi: 10.1093/oxfordhb/9780199733026.013.0032. 
Appendix 1. Instrument measuring environmental knowledge

- What does SDG refer to?

- Sustainable Development Goals ${ }^{\mathrm{a}}$.

- Supportive Development Goals.

- Sustainable Design Goals.

- What does sustainable development refer to?

- It is the constant economic development that seeks to increase markets related to recycling and the environment.

- It is the process of development that shows respect for the environment so that all generations can enjoy it.

- It is the process of development that satisfies present needs without compromising the needs of future generations, guaranteeing the balance between economic growth, environmental conservation and social well-being ${ }^{\mathrm{a}}$.

- How is nature-based education related to the SDG?

- Experiences in nature at an early age promote a pro-environmental and sustainable attitude in adulthood ${ }^{\mathrm{a}}$.

- Education in a natural setting helps save resources such as paper, light, heating and other materials.

- Nature-based schools are multiracial and multilingual, thus fostering an attitude of tolerance toward other cultures.

- What kind of waste can be flushed down the toilet?

- Toilet paper, swabs, tampons and makeup remover wipes.

- Toilet papera

- Toilet paper, wipes, oil and food scraps.

- What damage is caused by waste left in ditches along the road?

- Accidents and soil and road degradation.

- Traffic jams, fires, death of animals and contamination of soil and water ${ }^{\mathrm{a}}$.

- Fires and traffic jams.

- In Spain, the price of electricity is variable and influenced by the amount of renewable energy.

- No, what marks the electricity price is the amount of nuclear energy and gas we use.

- Yes, renewable energies are quite new, and thus, the more renewable energies we use, the higher the electricity price.

- Yes, the more renewable energies we use, the lower the electricity price ${ }^{\mathrm{a}}$.

- Regarding electric vehicles:

- They are sustainable and their carbon footprint depends on the manufacturing process and the type of energy source with which they are charged ${ }^{\mathrm{a}}$.

- They are sustainable and the carbon footprint is zero.

- They are sustainable but in the long term, they pollute more than a diesel cars.

- Which of the following daily life actions is most efficient to mitigate climate change:

- Recycling $100 \%$ of the paper, packaging and glass we generate.

- Eating a vegetable-based diet.

- Consuming energy from renewable energy sources ${ }^{\mathrm{a}}$. 


\section{IJSHE}

\section{- What does "circular economy" refer to?}

- It is an alternative to current economical processes aimed at optimizing the circulation of goods and services worldwide.

- It is an alternative to the linear economical model of extraction, production, consumption and throwing away ${ }^{\mathrm{a}}$.

- It is a new policy to make investments and provide aid at zero cost among the most disadvantaged social groups

\section{- Why should we switch to a circular economy?}

- Because of the increase in the demand for manufactured products and the need for speedy production.

- Because of the increase in the demand for raw materials and the scarcity of resources $^{\mathrm{a}}$.

- Because of the massive consumption of dairy products.

Note: ${ }^{\text {a }}$ Indicates correct response.

\section{Appendix 2}

\begin{tabular}{lccr}
\hline $\begin{array}{l}\text { Random effects } \\
\text { Group } \\
\text { Participant }\end{array}$ & Variance & SD & \\
Fixed effects & 0.00 & 0.00 & \\
& & & $t$ \\
Intercept & $\mathrm{b}$ & $95 \% \mathrm{CI}$ & 17.34 \\
T1 & 1.73 & {$[1.54-1.93]$} & 1.23 \\
T2 & 0.17 & {$[-0.10-0.45]$} & 1.44 \\
Experimental & 0.20 & {$[-0.20-0.48]$} & 0.38 \\
T1*Experimental & 0.08 & {$[0.65-1.43]$} & 5.19 \\
T2*Experimental & 1.04 & {$[0.35-1.14]$} & 3.72 \\
\hline
\end{tabular}

Random effects

Group

Participant

Fixed effects

Table A2.

Model for the personal environmental norms
Intercept

Intercept $\quad 3.73$

T1 0.05

T2 0.00

Experimental $\quad 0.01$

$\mathrm{T} 1 *$ Experimental $\quad 0.53$

$\mathrm{T} 2$ *Experimental $\quad 0.34$
Variance

0.20

SD

0.44

3.73
.05
.00
.01
.53
.34

$95 \% \mathrm{CI}$

$[3.52-3.93]$

$[-0.18-0.28]$

$[-0.23-0.23]$

$[-0.30-0.28]$

$[0.21-0.86]$

$[0.02-0.67]$ $t$

35.74

0.45

0.00

$-0.06$

3.22

2.06 


\title{
Sustainable development intervention
}

Random effects

Group

Participant

Fixed effects

Intercept

T1

T2

Experimental

T1*Experimental

T2*Experimental
Variance

0.20

b

3.40

0.12

$-0.03$

$-0.03$

0.83

0.69
SD

0.43

$$
\begin{gathered}
95 \% \mathrm{CI} \\
{[3.21-3.59]} \\
{[-0.09-0.32]} \\
{[-0.24-0.17]} \\
{[-0.30-0.24]} \\
{[0.54-1.12]} \\
{[0.40-0.98]}
\end{gathered}
$$

$t$

35.24

1.15

$-0.31$

$-0.24$

5.63

4.70
Table A3.

Model for the selfreported proenvironmental behaviors

\begin{abstract}
About the authors
Silvia Collado is a Senior Lecturer at the Department of Psychology and Sociology of Universidad de Zaragoza, Spain. She is interested in the study of the restorative effects of natural and built environments, environmental preferences and the factors shaping the development and change of environmental behaviors. She is especially interested in the examination of educational interventions that might prove effective in enhancing people's pro-environmentalism, as well as in translating research findings into specific guidelines for practitioners. Silvia Collado is the corresponding author and can be contacted at: scollado@unizar.es

José David Moreno is an Assistant Professor at the Cognitive Psychology Department of Universidad Autónoma de Madrid, Spain. His research interests are focused on the eye-tracking methodology applied to the scientific study of reading, text processing and reading comprehension in instructional contexts, computational models of language and also statistical modeling. He is especially interested in the analysis and improvement of reading processes and strategies in educational settings to enhance students' proficiency.

José Martín-Albo is a Senior Lecturer at the Department of Psychology and Sociology of Universidad de Zaragoza, Spain. He is interested in the study of the motivational and emotional processes that lead to academic achievement and students' well-being. He is also interested in sustainability issues and the promotion of a more sustainable society through the inclusion of environmentally friendly practices at a university level.
\end{abstract}

For instructions on how to order reprints of this article, please visit our website: 